\title{
Degradation of Reactive Dyes by Thermally Activated Persulfate and Reuse of Treated Textile Dye-Bath
}

\author{
Amanda O. Basilio, ${ }^{\circledR a}$ Lucas Dohler, ${ }^{b}$ Matheus Servin, ${ }^{b}$ Carlos A. K. Gouvea, ${ }^{b}$ \\ Ronny R. Ribeiro ${ }^{a}$ and Patricio Peralta-Zamora ${ }^{\circledR} * a$ \\ ${ }^{a}$ Departamento de Química, Universidade Federal do Paraná, CP 19081, 81531-980 Curitiba-PR, Brazil \\ ${ }^{b}$ Centro Universitário Sociesc (UNISOCIESC), CP 401, 89206-001 Joinville-SC, Brazil
}

\begin{abstract}
Due to the usual resistance of textile dyes to conventional biological treatment processes, the color removal of dyeing wastewaters remains a challenge for the textile industry. This work evaluates the capacity of advanced oxidation processes based on thermally-activated persulfate concerning textile dyes' degradation in aqueous solution and the reuse of dyeing baths. Preliminary studies were carried out in a bench-scale jacketed reactor, using Reactive Black 5 (40 $\left.\mathrm{mg} \mathrm{L}^{-1}\right)$ as a model dye. Almost complete dye degradation was observed in $60 \mathrm{~min}$ in this stage, using $300 \mathrm{mg} \mathrm{L}^{-1}$ of persulfate and activation temperatures of $80^{\circ} \mathrm{C}$, basically due to the action of radical sulfate. The use of high concentrations of persulfate $\left(1000 \mathrm{mg} \mathrm{L}^{-1}\right)$ allowed efficient color removal of dyeing baths containing remazol dyes in processes activated at 80 and $90{ }^{\circ} \mathrm{C}$. However, the wastewaters treated under these conditions did not lead to high dyeing efficiency in reuse studies, probably due to residual persulfate presence. In contrast, low concentrations of persulfate $\left(250 \mathrm{mg} \mathrm{L}^{-1}\right)$ lead to partial color removal and a better dyeing quality. The results suggest a good potential for treating high-temperature dyeing baths, saving water and auxiliary agents used in textile dyeing processes.
\end{abstract}

Keywords: thermally-activated persulfate, textile dyes, degradation, reuse

\section{Introduction}

In recent years, the use of dyes as a model substrate in degradation studies has been discouraged due to the self-sensitization observed in several photochemical processes. On the other hand, there is no way to ignore the high pollutant potential associated with the textile industry, mainly due to the discharge of high volumes of wastewater containing 10 to $50 \%$ of unfixed dyes. ${ }^{1}$ As a consequence, approximately 280,000 tons of dyes and other chemicals are introduced into the environment each year, ${ }^{2}$ with wellcharacterized harmful effects on aquatic ecosystems and human health. ${ }^{1}$ This problem is particularly relevant in countries that allow the use of azo dyes, which are resistant to biological treatment routines and have well-known chronic toxicity. ${ }^{3}$

Due to the potential toxicity of dyes, their efficient degradation in aqueous solution remains a relevant technological challenge, which has led to the proposal of many alternative treatments, including advanced oxidation processes (AOPs). Since 1990, when the use of AOPs

*e-mail: zamora@ufpr.br began to increase in environmental pollutants' degradation, thousands of papers have reported the efficiency of degradation of textile dyes by catalytic ozonation, ${ }^{4}$ heterogeneous photocatalysis, ${ }^{5}$ and Fenton reactions, ${ }^{6}$ among many other processes that involve the use of the combined technique.

According to the new concept of a circular economy, recycling and reusing inputs have become important in the textile industry context. ${ }^{7}$ Thus, efforts have been made to ensure water conservation, including adopting innovative wastewater treatment processes. ${ }^{8}$ For this purpose, many physical, biological, and chemical processes have been proposed, ${ }^{9}$ with the advantage of methods that combine preliminary oxidation by advanced oxidation processes, for example, followed by traditional biological processes. ${ }^{10}$

Since the 2000s, many papers have reported efficient degradation of dyes by persulfate-mediated processes activated by ultraviolet radiation, ${ }^{11}$ ultrasound, ${ }^{12}$ and a wide variety of materials containing various iron forms. ${ }^{13,14} \mathrm{In}$ the context of thermally activated processes, several studies report efficient degradation of dyes in aqueous solution, such as methylene blue, ${ }^{15}$ safranin $\mathrm{O},{ }^{16}$ acid blue $92,{ }^{17}$ and acid blue $113 .{ }^{18}$ Additionally, a recent work ${ }^{19}$ reports the 
treatment of dyeing baths containing azo dyes by ozone and heat-activated persulfate, with results that show a higher efficiency of the process mediated by persulfate.

In the particular case of dyeing waste, the complexity of the dyebaths, which usually contain mixtures of residual dyestuff, high concentration of salts $\left(\mathrm{NaCl}, \mathrm{Na}_{2} \mathrm{SO}_{4}\right.$, and $\mathrm{Na}_{2} \mathrm{CO}_{3}$ ), enzymes, and other dyeing auxiliaries, such as dye-fixing agent, optical brighteners, finishing chemicals, etc., can compromise the efficiency of chemical oxidation systems.

Giving these statements, the present study's objective was to evaluate the potential of the thermally-activated persulfate oxidation system in the treatment of dyeing wastewater, aiming at the reuse of the treated wastewater in new dyeing cycles. Preliminary studies involving aqueous solutions of a model dye (Reactive Black 5) were carried out to evaluate the effect of relevant operational variables on the process's degradation capacity and to investigate the participation of radical forms.

\section{Experimental}

\section{Materials}

Water used was purified by a Millipore reverse osmosis (RO) purification system (water (Milli-Q, 18.2 $\mathrm{M} \Omega \mathrm{cm}$, Millipore-Simplicity UV)). Potassium persulfate (PS) ( $\geq 99.0 \%)$ was purchased from Merck (Darmstadt, Germany); sodium thiosulfate (TS) $(99.5 \%)$ and potassium iodide (KI) (> 99.0\%) were purchased from Neon (Suzano, Brazil); Reactive Black 5 (RB5) $(\geq 50.0 \%)$ and tert-butyl alcohol (TBA) (99.0\%) were purchased from Sigma-Aldrich (Saint Louis, USA); ethanol absolute (EtOH) (> 99.9\%) was purchased from J.T. Baker (Phillipsburg, USA).

5,5-Dimethyl-1-pyrroline $N$-oxide (DMPO) ( $\geq 98.0 \%$ ) employed in electron paramagnetic resonance (EPR) studies was acquired from Santa Cruz Biotechnology (Dallas, USA) and diluted to $346 \mathrm{mmol} \mathrm{L}^{-1}$ in ultrapure water and dimethyl sulfoxide (DMSO) (99.9\%) was purchased from Synth (Diadema, Brazil).

\section{Experimental procedure}

RB5 solution was prepared at an initial concentration of $40.0 \mathrm{mg} \mathrm{L}^{-1}\left(0.040 \mathrm{mmol} \mathrm{L}^{-1}\right)$. A $2^{3}$ full-factorial design with two levels and a central point (Table 1) was used to evaluate the influence of the experimental variables: initial persulfate concentration $\left(\mathrm{C}_{\mathrm{PS}}\right), \mathrm{pH}$, and temperature $(\mathrm{T})$. Experiments (1 to 8$)$ were done in a random sequence, and the central point triplicate (experiments 9-11) was made on the same day. For each designed experiment, reaction solutions were prepared and poured into a $100 \mathrm{~mL}$ bench-scale jacket reactor and monitored for $120 \mathrm{~min}$. Similar experiments employing TBA and EtOH as scavenging agents were designed to identify the major radical species. In these studies, $1 \mathrm{~mL}$ of $100 \mathrm{mmol} \mathrm{L}^{-1}$ aqueous alcohol solution was added before persulfate in the RB5 solution.

Table 1. Factors, levels, and experimental matrix of the $2^{3}$ full-factorial design used to evaluate the effects of experimental variables on the degradation of the model dye (Reactive Black 5) by thermally-activated persulfate system

\begin{tabular}{lccc}
\hline Experiment & Temperature $/{ }^{\circ} \mathrm{C}$ & $\begin{array}{c}\text { Persulfate } \\
\text { concentration }\left(\mathrm{C}_{\mathrm{PS}}\right) \\
/\left(\mathrm{mg} \mathrm{L}^{-1}\right)\end{array}$ & $\mathrm{pH}$ \\
\hline 1 & $50.0(-1)$ & $100(-1)$ & $4.00(-1)$ \\
2 & $80.0(+1)$ & $100(-1)$ & $4.00(-1)$ \\
3 & $50.0(-1)$ & $300(+1)$ & $4.00(-1)$ \\
4 & $80.0(+1)$ & $300(+1)$ & $4.00(-1)$ \\
5 & $50.0(-1)$ & $100(-1)$ & $8.00(+1)$ \\
6 & $80.0(+1)$ & $100(-1)$ & $8.00(+1)$ \\
7 & $50.0(-1)$ & $300(+1)$ & $8.00(+1)$ \\
8 & $80.0(+1)$ & $300(+1)$ & $8.00(+1)$ \\
$9-11$ & $65.0(0)$ & $200(0)$ & $6.00(0)$ \\
\hline
\end{tabular}

The coded values are indicated in parentheses.

At designated time intervals, $3.00 \mathrm{~mL}$ aliquots of the reaction solution were collected in a $10.0 \mathrm{~mL}$ test tube preloaded with $100 \mu \mathrm{L}\left(6.00 \mathrm{mmol} \mathrm{L}^{-1}\right)$ of sodium thiosulfate, which was used as a quenching agent to terminate the RB5-PS reaction by reducing the residual persulfate to sulfate. Control experiments in the absence of the oxidant were also conducted under two different experimental conditions.

\section{Analytical method (chemical analysis)}

RB5 concentrations were determined on a Varian Cary 50 Bio UV-Vis spectrophotometer, using quartz cuvettes $(1 \mathrm{~cm})$. The discoloration was evaluated based on the absorbance values registered at $595 \mathrm{~nm}$, while mineralization was estimated based on the integrated spectral area between 200 and $800 \mathrm{~nm}$. PS concentration was monitored through colorimetric reaction with $\mathrm{KI} 2.50 \%(\mathrm{~m} / \mathrm{v})$, as described by Liang et al..$^{20}$ The active radicals (hydroxyl and sulfate radicals) were detected by spin trapping with DMPO (4.00 $\mathrm{mmol} \mathrm{L}^{-1}$ ) in an X-band EPR spectrometer (Bruker EMX micro). Semi-quantitative EPR measurements were performed using a powder sample of homemade chromium $\left(\mathrm{Cr}^{3+}\right)$ doped magnesium oxide as an intensity standard. For the EPR measurements, reactions were carried out in 
capillary tubes sealed with $3.0 \mu \mathrm{L}$ of the reaction mixture (PS and DMPO). The capillary tubes were heated at selected temperatures and, at regular intervals, each tube was coupled to the EPR resonator. EPR spectrometer settings were: microwave power $5 \mathrm{~mW}$; microwave frequency 9.759 GHz; modulation amplitude $1.00 \mathrm{G}$; magnetic field scan $154.7 \mathrm{G}$; sweep time $41.94 \mathrm{~s}$; time constant $2.56 \mathrm{~ms}$; and 10 accumulations. Simulations were performed using the EasySpin $^{21}$ toolbox in the Matlab ${ }^{22}$ environment. The kinetic fits were performed on the graphs of RB5 concentration versus time of reaction, using OriginPro 9.0.2.

\section{Preparation of dyeing effluent}

The dyeing effluent proposed in this study is equivalent to the vast majority of residual dyeing baths generated in dyeing cotton fabrics with reactive dyes, ${ }^{24,25}$ consisting of three vinyl sulfone $\left(\right.$ Remazol $\left.^{\circledR}\right)$ dyes (RGBN yellow, RGB red, and RGB navy blue) in a concentration of $50.0 \mathrm{mg} \mathrm{L}^{-1}$, $30.0 \mathrm{~g} \mathrm{~L}^{-1}$ of sodium sulfate, $1.00 \mathrm{~mL} \mathrm{~L}^{-1}$ of a dispersing agent (Albatex $\left.{ }^{\circledast} \mathrm{CP}\right), 0.30 \mathrm{~mL} \mathrm{~L}^{-1}$ of a catalyst enzyme (Rucogreen ${ }^{\circledast}$ B-CAT), $0.50 \mathrm{~mL} \mathrm{~L}^{-1}$ of a cellulase enzyme (Chimilase ${ }^{\circledR} \mathrm{NEU}$ ) and $10.0 \mathrm{~g} \mathrm{~L}^{-1}$ of sodium carbonate. The bath was heated to $60.0 \pm 3.00{ }^{\circ} \mathrm{C}$, promoting hydrolysis reactions, and remained at this temperature for $90 \mathrm{~min}$. Finally, the wastewater was cooled and stored in the dark at $4.00{ }^{\circ} \mathrm{C}$.

\section{Dyebath treatment}

All discoloration tests were performed in triplicate, using slow and constant magnetic stirring (200 rpm). In a typical assay, $100 \mathrm{~mL}$ of dyeing effluent was added to potassium persulfate solutions in concentrations of 0.25 , 0.50 , and $1.00 \mathrm{~g} \mathrm{~L}^{-1}$ and heated to 75,85 , and $95{ }^{\circ} \mathrm{C}$ up to $120 \mathrm{~min}$. Aliquots were taken at regular intervals and analyzed by UV-Vis spectrophotometry on HACK 5000 equipment. The discoloration was expressed in percentage terms, based on the absorbance value recorded at $595 \mathrm{~nm}$ in $1 \mathrm{~cm}$ cuvettes.

\section{Reuse of treated dyebath}

Bench-scale dyeing was performed on a MATHIS ALT-1 dyeing machine with a capacity of $150 \mathrm{~mL}$. Initially, $10.0 \mathrm{~g}$ of $100 \%$ bleached fuzzy cotton $\left(380 \mathrm{~g} \mathrm{~m}^{-2}\right)$ was immersed in the dyeing bath containing $100 \mathrm{~mL}$ of water (or treated dyebath), $1.00 \mathrm{~g}$ of sodium sulfate, $1.00 \mathrm{~mL}$ of dispersant (Albatex ${ }^{\circledast} \mathrm{CP} 10 \%$ solution), $4.90 \mathrm{~mL}$ of RGBN yellow (1\% solution), $2.30 \mathrm{~mL}$ RGB red (1\% solution), and $4.10 \mathrm{~mL}$ RGB navy blue ( $1 \%$ solution). Then, the bath temperature was increased to $60.0{ }^{\circ} \mathrm{C}$ and maintained for $30 \mathrm{~min}$. Later, $0.500 \mathrm{~g}$ of sodium carbonate and $0.240 \mathrm{~g}$ of sodium hydroxide $50 \%$ were added to the bath, remaining at $60.0^{\circ} \mathrm{C}$ for another $30 \mathrm{~min}$. The bath was discarded after dyeing, and the substrate was neutralized in a cold acetic acid bath. Finally, the dyed fabric was washed two times at $80.0{ }^{\circ} \mathrm{C}$ to remove the hydrolyzed dyes.

The dyeing process's quality was evaluated as a function of the color deviation $(\Delta \mathrm{E})$ and the coloristic strength $(\mathrm{K} / \mathrm{S})$, calculated from measurements carried out on a Datacolor Spectraflash SR450 spectrophotometer. The color deviation was calculated based on the expression shown in equation 1 , in which: $\Delta \mathrm{H}$ corresponds to the tonality deviation, $\Delta \mathrm{C}$ to the purity deviation, and $\Delta \mathrm{L}$ to the clarity deviation. Kubelka-Munke equation (equation 2) gives the coloristic strength, in which: K corresponds to the light absorption from the dye, $\mathrm{S}$ to the light diffusion from the substrate, and $\mathrm{R}$ to the remission value.

$\Delta \mathrm{E}=\left[(\Delta \mathrm{H})^{2}+(\Delta \mathrm{C})^{2}+(\Delta \mathrm{L})^{2}\right]^{1 / 2}$

$\mathrm{K} / \mathrm{S}=\left[(1-\mathrm{R})^{2}\right] / 2 \mathrm{R}$

\section{Results and Discussion}

Influence of experimental variables on the degradation of the model dye (RB5)

The $2^{3}$ full factorial design (Table 2) shows the matrix used to calculate the first, second, and third-order effects (Table 3), according to equation 3. Persulfate-mediated degradation processes usually follow a pseudo-first-order kinetic, and the rate constant of each experiment is used to calculate the effects. Unfortunately, the kinetic adjustment could not be made for reactions carried out in low degradation conditions (see Figure S2, Supplementary Information (SI) section). Thus, the effects were calculated from the degradation percentage measured after 5 min of treatment.

$\operatorname{Effect}(\mathrm{X})=\frac{\left(\sum \mathrm{Y}+\right)-\left(\sum \mathrm{Y}-\right)}{4}$

where $\mathrm{Y}-$ represents the answer obtained at level (-) of the variable $\mathrm{X}$, and $\mathrm{Y}+$ is the answer obtained at level (+).

According to the results (Figures $1 \mathrm{a}$ and $1 \mathrm{~b}$, main effects; $1 \mathrm{c}$, second-order effects), the temperature has shown a substantial effect on the degradation of the model dye (36.3 percentage points), which indicates the necessity of high thermal energy to overcome the energy barrier that leads to the homolytic scission of the persulfate anion (equation 4).

$\mathrm{S}_{2} \mathrm{O}_{8}{ }^{2-}{ }_{(\mathrm{aq})}+$ heat $\rightarrow 2 \mathrm{SO}_{4}{ }^{-}{ }_{(\text {aq })}$ 
Table 2. Factors, levels, experimental matrix, and results of the $2^{3}$ full-factorial design used to evaluate the effects of experimental variables on the degradation of the model dye (Reactive Black 5) by thermally-activated persulfate system

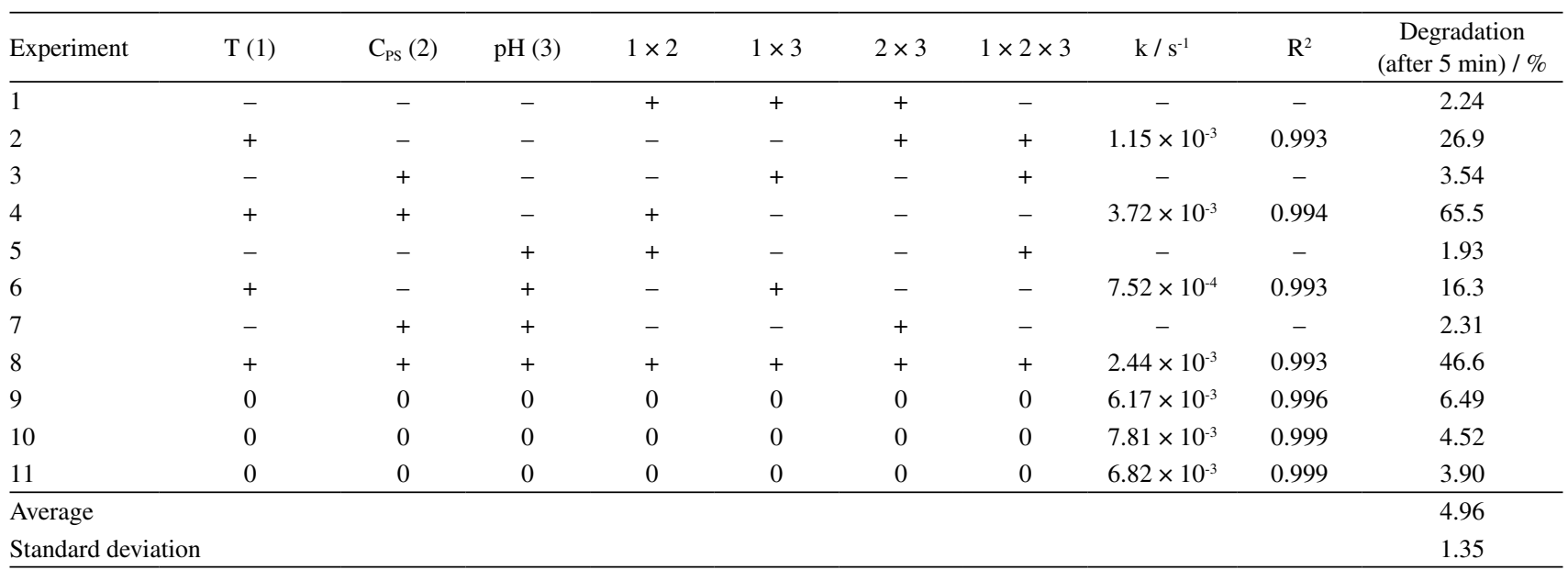

$\mathrm{T}$ : temperature; $\mathrm{C}_{\mathrm{PS}}$ : initial persulfate concentration; $\mathrm{k}$ : pseudo-first-order rate constant; $\mathrm{R}^{2}$ : determination coefficient.

Table 3. First, second, and third-order effects for the $2^{3}$ full-factorial design

\begin{tabular}{lcc}
\hline \multicolumn{3}{c}{ First-order effects } \\
\hline $\mathrm{T}$ & 36.3 \\
$\mathrm{C}_{\mathrm{PS}}$ & 17.6 \\
$\mathrm{pH}$ & -7.77 \\
\hline \multicolumn{3}{c}{ Second-order effects } \\
\hline $\mathrm{T} \times \mathrm{C}_{\mathrm{PS}}$ & 16.8 \\
$\mathrm{~T} \times \mathrm{pH}$ & -28.0 \\
$\mathrm{C}_{\mathrm{PS}} \times \mathrm{pH}$ & -2.30 \\
\hline & \\
\hline $\mathrm{T} \times \mathrm{C}_{\mathrm{PS}} \times \mathrm{pH}$ & Third-order effects \\
$\mathrm{s} \times t_{95 \%}$ & & -1.83 \\
\hline
\end{tabular}

T: temperature; $\mathrm{C}_{\mathrm{PS}}$ : initial persulfate concentration; $\mathrm{s}$ : standard deviation of the central point triplicate; $t$ : critical value of $t$ for $\mathrm{N}-1$ and $95 \%$ of confidence level.

The increase in the initial concentration of persulfate also favors the degradation of the model dye (effect of 17.6 percentage points), which is commonly observed in radical reactions of this nature. In general, the increase in the amount of reagent favors the degradation of the target molecule, up to the limit where the excess of reagent (or formed radicals) promotes scavenging effects. ${ }^{26,27}$

Generally, it is assumed that the alkaline medium favors persulfate-mediated reactions due to the alkaline activation of persulfate (equation 5) and further generation of hydroxyl radical (equation 6). However, under the conditions applied in this work, the $\mathrm{pH}$ showed a negative effect ( -7.8 percentage points), which implies a more remarkable ability for degradation in an acidic medium ( $\mathrm{pH} 4.00)$. Once this medium favors the permanence and the action of sulfate radical, this result suggests relevant participation of this species in the degradation of the model dye. ${ }^{28}$

$$
\begin{aligned}
& 2 \mathrm{~S}_{2} \mathrm{O}_{8}{ }^{2-}+2 \mathrm{H}_{2} \mathrm{O} \stackrel{\mathrm{OH}^{-}}{\rightarrow} 3 \mathrm{SO}_{4}{ }^{2-}+\mathrm{SO}_{4}^{-\cdot}+\mathrm{O}_{2}^{-{ }^{-}}+4 \mathrm{H}^{+} \\
& \mathrm{SO}_{4}^{-}+\mathrm{OH}^{-} \rightarrow \mathrm{HO}^{-}+\mathrm{SO}_{4}{ }^{2-}
\end{aligned}
$$

The geometric representation shown in Figure 1 demonstrates that the initial concentration of persulfate and the $\mathrm{pH}$ are relevant only at high temperatures, which
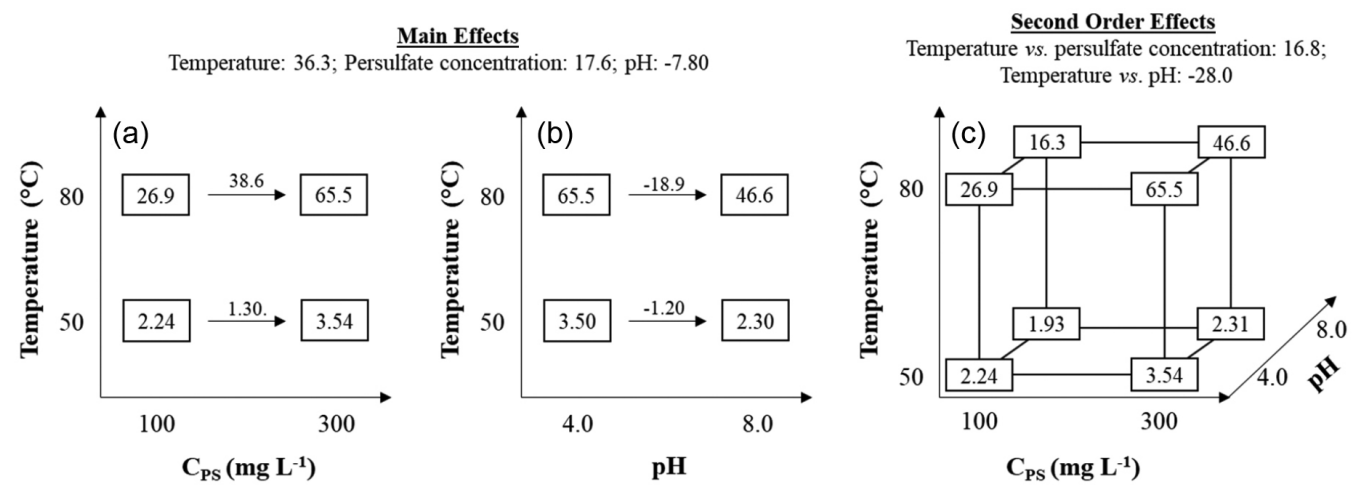

Figure 1. Geometric representation of the $2^{3}$ full-factorial design used to evaluate the effects of experimental variables on the degradation of the model dye (Reactive Black 5, $\mathrm{C}_{\mathrm{RB} 5}=40.0 \mathrm{mg} \mathrm{L}^{-1}$ ) by thermally-activated persulfate system. 
characterizes a second-order effect and indicates the need for higher temperatures than those at the central point $\left(65.0^{\circ} \mathrm{C}\right)$.

According to the changes observed in the model dye's UV-Vis spectrum during treatment in the best degradation condition (Figure 2), the main chromophore group's signal decreases rapidly in the initial degradation stage (5-15 min). Concomitantly, there is an appearance of a less defined band at shorter wavelengths, which accounts for the color transition observed during the process (blue, purple, red, colorless). This hypochromic shift was also noticed by Rao et al. ${ }^{29}$ in studies of degradation of RB5 by $\mathrm{CuO}$-mediated photocatalysis.

As reported by Jager et al. ${ }^{30}$ in a study about the electrochemical degradation of RB5, the purple staining observed in the early stages of the degradation results from the presence of an isoxazole derivative generated by an intramolecular cyclization mediated by the hydroxyl radical. These compounds were also observed in studies conducted by Bhaumik et al. ${ }^{31}$ regarding the RB5 degradation by processes catalyzed by $\mathrm{Fe}-\mathrm{TiO}_{2}$ and assisted by ultrasound.

At prolonged treatments ( $60 \mathrm{~min})$, the color was removed entirely, which implies the azo bonds' cleavage and the dye molecule fragmentation. However, residual absorption observed at wavelengths shorter than $300 \mathrm{~nm}$ indicates the persistence of aromatic fragments. According to Joseph et al., ${ }^{32}$ the most labile sites for the oxidative attack of the RB5 are positioned $1,4,9,15$, and 24 , therefore leading to the cleavage of $\mathrm{C}(4)-\mathrm{N}(7), \mathrm{C}(9)-\mathrm{N}(8), \mathrm{C}(15)-\mathrm{N}(19)$, and $\mathrm{C}(21)-\mathrm{N}(20)$ bonds. Thus, the initial products of RB5 degradation correspond to sulfonated aromatic amines, such as 3,4,6-triamino-5-hydroxynaphthalene-2,7-disulfonate and 2-[(4-aminophenyl) sulphonyl) ethyl sulfate, which, in later stages, can lead to the generation of species such as 3,6,8-triaminonaphthalen-1-ol, and isobenzofuran1,3-dione, respectively. ${ }^{33}$ In the final stages, simpler compounds appear, such as naphthol, benzoic acid, phenol, and phthalic acid. ${ }^{34}$

In studies involving the degradation of benzoic acid by thermally-activated persulfate processes, 25 by-products generated by decarboxylation and hydroxylation reactions were identified. Some of these by-products, as hydroxybenzoic acids and phenol, persisted even after longer reaction times $(8 \mathrm{~h})$, which justifies the permanence of aromatic species as those identified in the study. ${ }^{35}$

It is possible to estimate the total organic carbon content from the signal recorded by UV-Vis spectroscopy in many cases ${ }^{36,37}$ Likewise, previous experience involving the degradation of dyes indicates an excellent correlation between the mineralization of the molecule and the integrated spectral area between 200 and $800 \mathrm{~nm}$. In this case, $60 \mathrm{~min}$ treatments caused a reduction of approximately $60 \%$ in the spectral area, which suggests only partial mineralization of the dye molecule. In treatments of $120 \mathrm{~min}$, the decline in the spectral area reached values not exceeding $80 \%$ due to the persistence of signals that can be associated with benzenoid compounds, such as phenol.

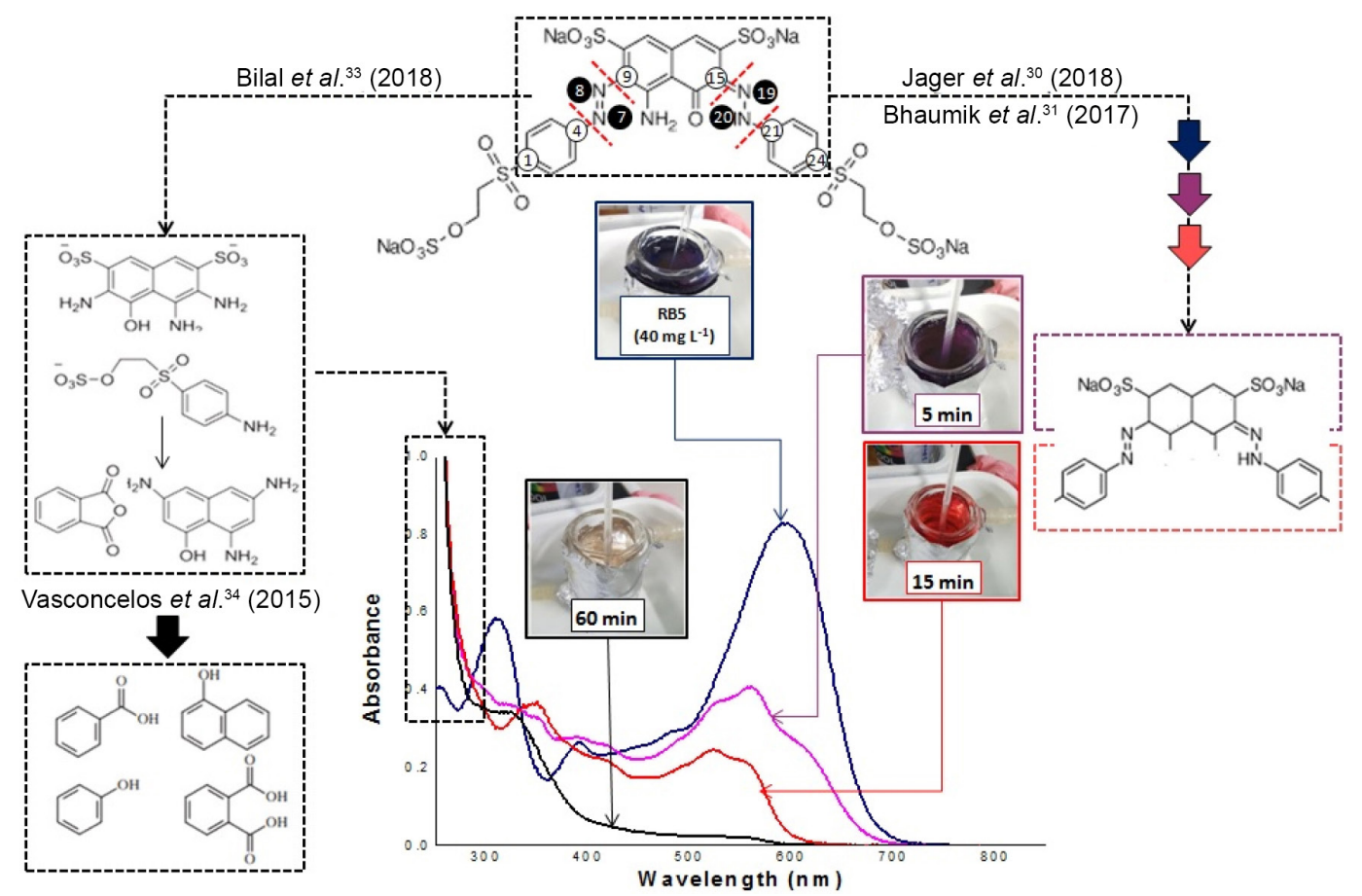

Figure 2. Degradation profile and color evolution during the degradation of Reactive Black $5\left(40 \mathrm{mg} \mathrm{L}^{-1}\right)$ by thermally-activated persulfate (experimental conditions: $\left.\mathrm{T}=80^{\circ} \mathrm{C}, \mathrm{C}_{\mathrm{PS}}=300 \mathrm{mg} \mathrm{L}^{-1}, \mathrm{pH}=4.0\right)$ and possible transient species based on literature background..$^{30,31,33,34}$ 


\section{Identification of radical species}

In this stage, radical scavengers' presence in the degradation reactions evaluated radical species' participation in the process. The identification of the radicals was performed using the EPR spectroscopy technique.

\section{Degradation in the presence of radical scavengers}

Fundamentally, there are two radical species involved in the degradation processes mediated by activated-persulfate: sulfate radical, which is formed by the homolytic scission of the persulfate anion (equation 4), and hydroxyl radical, which results from the reaction between sulfate radical and hydroxide anion in alkaline medium (equation 6).

Radical scavenging assessments were carried out using tert-butyl alcohol (TBA) and ethanol (EtOH), both under two $\mathrm{pH}$ conditions (4.00 and 8.00), to identify the dominant oxidizing species $\left(\mathrm{SO}_{4}^{-} v s\right.$. $\left.\mathrm{HO}^{*}\right)$. According to data compiled by Anipsitakis and Dionysiou, ${ }^{38}$ the hydrogen abstraction from EtOH shows similar rate constants with hydroxyl $\left(\mathrm{k}_{\mathrm{EtOH}}=1.2-2.8 \times 10^{9} \mathrm{~L} \mathrm{~mol}^{-1} \mathrm{~s}^{-1}\right)$ and sulfate $\left(\mathrm{k}_{\mathrm{EtOH}}=1.6-7.7 \times 10^{8} \mathrm{~L} \mathrm{~mol}^{-1} \mathrm{~s}^{-1}\right)$ radicals, which enables its use as a scavenging agent for both radicals. ${ }^{39}$ On the other hand, the reaction between TBA and hydroxyl radicals $\left(\mathrm{k}_{\mathrm{TBA}}=3.8-7.6 \times 10^{8} \mathrm{~L} \mathrm{~mol}^{-1} \mathrm{~s}^{-1}\right)$ is kinetically more favorable than that with sulfate radical $\left(\mathrm{k}_{\mathrm{TBA}}=4.0-9.1 \times 10^{5} \mathrm{~L} \mathrm{~mol}^{-1} \mathrm{~s}^{-1}\right)$, which allows for its use to evaluate the single contribution of hydroxyl radicals.

As shown in Figure 3a, at $\mathrm{pH} 4.0$, the removal of RB5 was significantly reduced in the presence of EtOH, suggesting that both radicals could play an essential role in the degradation process. In contrast, the presence of TBA resulted in a weak inhibitory effect, which indicates an irrelevant contribution of the hydroxyl radical. These results agree with studies in which more significant

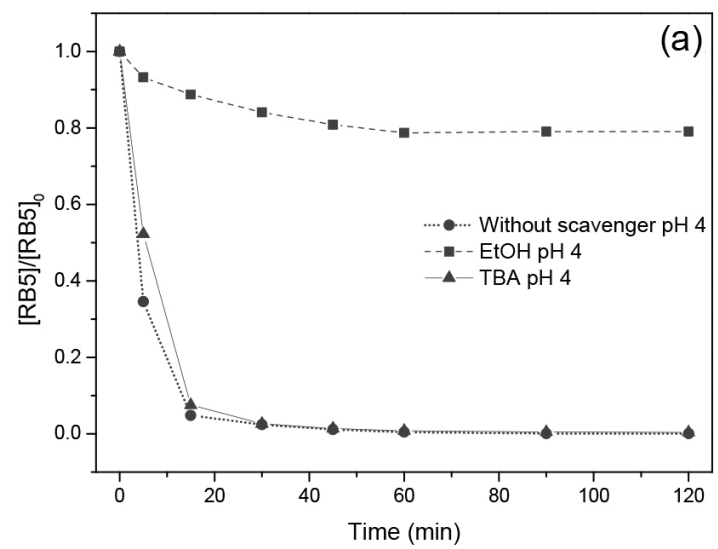

activity was reported for the sulfate radical in persulfatebased AOPs, both in acidic and neutral medium. ${ }^{28}$ At $\mathrm{pH}$ 8.0 (Figure $3 b$ ), the inhibitory effect of TBA is more extensive, which indicates a better performance of the hydroxyl radical under alkaline conditions, as observed by Ike et $a l .^{28}$

In the absence of scavengers, dye degradation is practically complete around $30 \mathrm{~min}$, at both $\mathrm{pH}$ values. However, as observed in preliminary studies, the reaction occurs quicker in an acidic medium, which again suggests the relevant contribution of sulfate radical.

\section{EPR characterization}

Since AOPs involve short-lived radical species production, the EPR spin-trapping technique using DMPO is a handy characterization tool to investigate such systems. DMPO forms adducts with hydroxyl and sulfate radicals, generating classic spectra containing 4 and 6 lines, with intensities $1: 2: 2: 1^{40}$ and $1: 1: 1: 1: 1: 1,{ }^{41}$ respectively.

The EPR investigations started evaluating the effects of temperature $\left(50.0\right.$ and $80.0^{\circ} \mathrm{C}$ ) and persulfate concentration (100 and $300 \mathrm{mg} \mathrm{L}^{-1}$ ) on the radical formation. The obtained spectra were normalized to the reference signal so that the relative adduct concentration and, therefore, the radical concentration could be determined.

According to the results shown in Figure $4 \mathrm{a}$, the -DMPO-OH signal increases about 22 times when the temperature is raised from 50.0 to $80.0{ }^{\circ} \mathrm{C}$, which corroborates the effects observed in the preliminary factorial design, thus confirming the need for higher temperatures to reach the persulfate decomposition activation energy. In contrast, the intensity ratio shown in Figure $4 \mathrm{~b}$ reveals that a 3-fold increase in the concentration of persulfate leads to a 6 -fold increase in the intensity of the adduct $\cdot \mathrm{DMPO}-\mathrm{OH}$ signal, which suggests that higher temperatures favor the

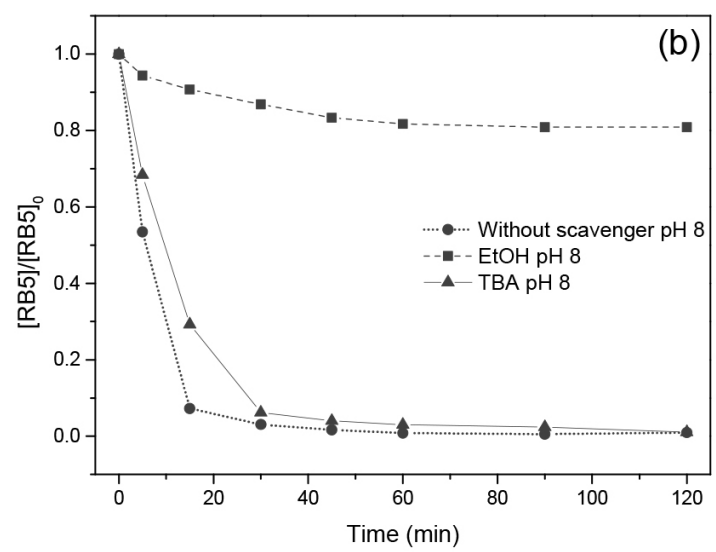

Figure 3. Degradation of Reactive Black $5\left(40.0 \mathrm{mg} \mathrm{L}^{-1}\right)$ by thermally-activated persulfate $\left(\mathrm{C}_{\mathrm{PS}}=300 \mathrm{mg} \mathrm{L}^{-1}, \mathrm{~T}=80.0^{\circ} \mathrm{C}\right)$ in the presence and absence of radical scavengers at $\mathrm{pH} 4.00$ (a) and $\mathrm{pH} 8.00$ (b). 
hydroxyl radical formation, even at lower concentrations of persulfate.

Although studies involving scavenging agents have clearly shown sulfate radical activity, EPR studies have confirmed only the adduct's presence resulting from the reaction between DMPO and hydroxyl radical. Explaining the absence of the sulfate radical spectrum requires resorting to kinetic aspects related to radicals and adducts' formation and stability, based on the reactions shown below.

$$
\begin{array}{r}
\mathrm{SO}_{4}^{-\bullet}+\mathrm{H}_{2} \mathrm{O} \rightarrow \mathrm{H}^{+}+\mathrm{HO}^{\bullet}+\mathrm{SO}_{4}{ }^{2-} \\
\mathrm{k}=1.6 \times 10^{5} \mathrm{~s}^{-1}
\end{array}
$$

$$
\begin{aligned}
\mathrm{DMPO}+\mathrm{SO}_{4}^{-} \rightarrow & \cdot{ }^{-\mathrm{DMPO}}-\mathrm{SO}_{4}^{-} \\
\mathrm{k} & =2.9 \times 10^{4} \mathrm{~L} \mathrm{~mol}^{-1} \mathrm{~s}^{-1}
\end{aligned}
$$

$$
\begin{gathered}
\cdot \text { DMPO- } \mathrm{SO}_{4}{ }^{-}+\mathrm{H}_{2} \mathrm{O} \rightarrow \cdot \text { DMPO-OH }+\mathrm{H}^{+}+\mathrm{SO}_{4}{ }^{2-} \\
\mathrm{k}=8.9 \times 10^{2} \mathrm{~s}^{-1}
\end{gathered}
$$

$\mathrm{DMPO}+\mathrm{HO} \cdot \rightarrow \cdot \mathrm{DMPO}-\mathrm{OH}$

$$
\mathrm{k}=2.8 \times 10^{9} \mathrm{~L} \mathrm{~mol}^{-1} \mathrm{~s}^{-1}
$$

According to the second-order rate constants reported by Wei et al.., ${ }^{42}$ and Taniguchi and Madden, ${ }^{43}$ the direct formation of the $\cdot \mathrm{DMPO}-\mathrm{OH}$ adduct is 100,000 times faster than the ${ }^{-D M P O}-\mathrm{SO}_{4}{ }^{-}$adduct, indicating that even in the presence of sulfate radical, the appearance of $\bullet \mathrm{DMPO}-\mathrm{OH}$ will be favored. Moreover, both the sulfate radical and its adduct can undergo hydrolysis reactions that lead to the generation of hydroxyl radical and its adduct, respectively. Hydrolysis of $\mathrm{SO}_{4}^{-}$, however, is faster than the adduct's hydrolysis, favoring the formation of $\mathrm{HO}^{*}$ before the reaction between $\mathrm{SO}_{4}{ }^{-}$and DMPO. Hence, the generation of sulfate radical cannot be verified by EPR in reactions conducted in an aqueous medium.

Following procedures reported by Zalibera et al., ${ }^{41}$

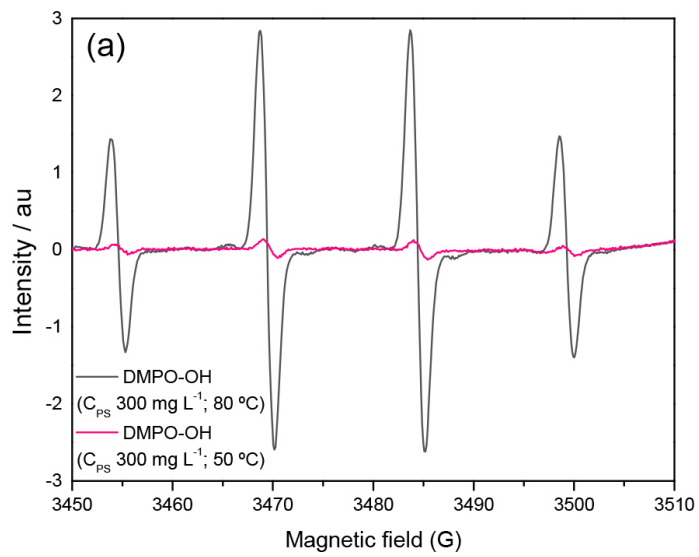

EPR characterization studies were carried out in DMSO to demonstrate that the sulfate radical is the primary reactive species in the process. Under these conditions, the hydrolysis reactions were inhibited, and it was possible to acquire the classic 6-line spectrum of the sulfate radical, which was confirmed by spectral simulations (see Figure S3, SI section).

\section{Treatment and reuse of dyebath}

In preliminary studies, using persulfate at concentrations of $300 \mathrm{mg} \mathrm{L}^{-1}$ and activation temperatures of $80.0^{\circ} \mathrm{C}$ shows a higher degradation efficiency. During dyebath treatment, higher concentrations $(250,500$, and $\left.1000 \mathrm{mg} \mathrm{L}^{-1}\right)$ and temperatures $\left(75.0,80.0\right.$, and $90.0^{\circ} \mathrm{C}$ ) were used to overcome the negative scavenging effect caused by the presence of salts and auxiliary agents in the dyeing bath.

According to the results summarized in Figure 5, temperatures below $80^{\circ} \mathrm{C}$ delay the discoloration process, even with high persulfate concentrations. On the other hand, in the processes activated at 80.0 or $90.0^{\circ} \mathrm{C}$, the color is quickly removed, practically without the influence of persulfate concentration.

According to international standards (DIN 6174, 1979),${ }^{44} \Delta \mathrm{E}$ values between 1.5 and 3.0 correspond to perceptible color differences. Therefore, export textile products must have a $\Delta \mathrm{E}<1.0$. However, considering the human eye's ability to discriminate colors, $\Delta \mathrm{E}$ values below 2.0 are usually regarded as satisfactory for products sold in the national market. In contrast, values between 2.0 and 5.0 are considered "conditionally accepted" depending on the customer's requirement criteria. The results shown in Figure 6 indicate that the processes activated at 75 and $80{ }^{\circ} \mathrm{C}$ lead to minor color differences using the lowest persulfate concentration $\left(250 \mathrm{mg} \mathrm{L}^{-1}\right)$. Although the color removal was only partial under these conditions, the reuse

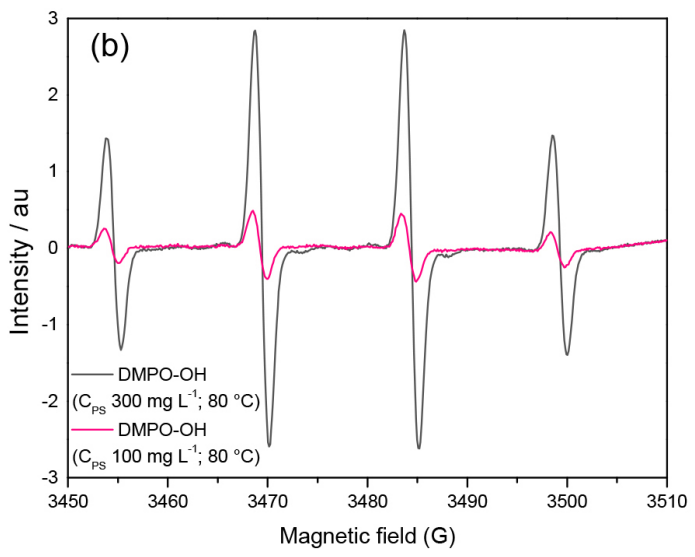

Figure 4. EPR spectra of the $\cdot \mathrm{DMPO}-\mathrm{OH}$ adduct acquired in aqueous solution at $298 \mathrm{~K}$. (a) Effect of activation temperature $\left(\mathrm{C}_{\mathrm{PS}}=300 \mathrm{mg} \mathrm{L}^{-1}\right.$, $\left.\mathrm{C}_{\mathrm{DMPO}}=20.0 \mathrm{mM}\right)$ and (b) effect of persulfate concentration $\left(\mathrm{T}=80.0^{\circ} \mathrm{C}, \mathrm{C}_{\mathrm{DMPO}}=20.0 \mathrm{mM}\right)$. 


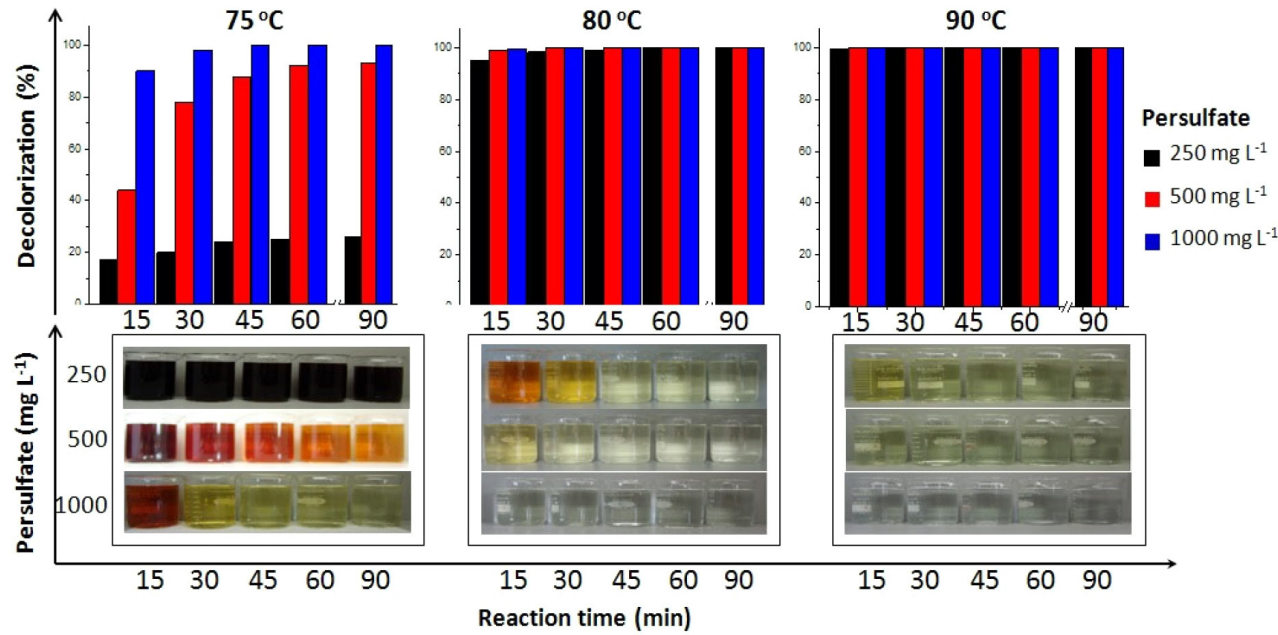

Figure 5. Decolorization of the dyebath by thermally-activated persulfate $\left(\mathrm{C}_{\mathrm{PS}}=250,500\right.$, and $1000 \mathrm{mg} \mathrm{L}^{-1} ; \mathrm{T}=75.0,80.0$, and $\left.90.0{ }^{\circ} \mathrm{C}\right)$.

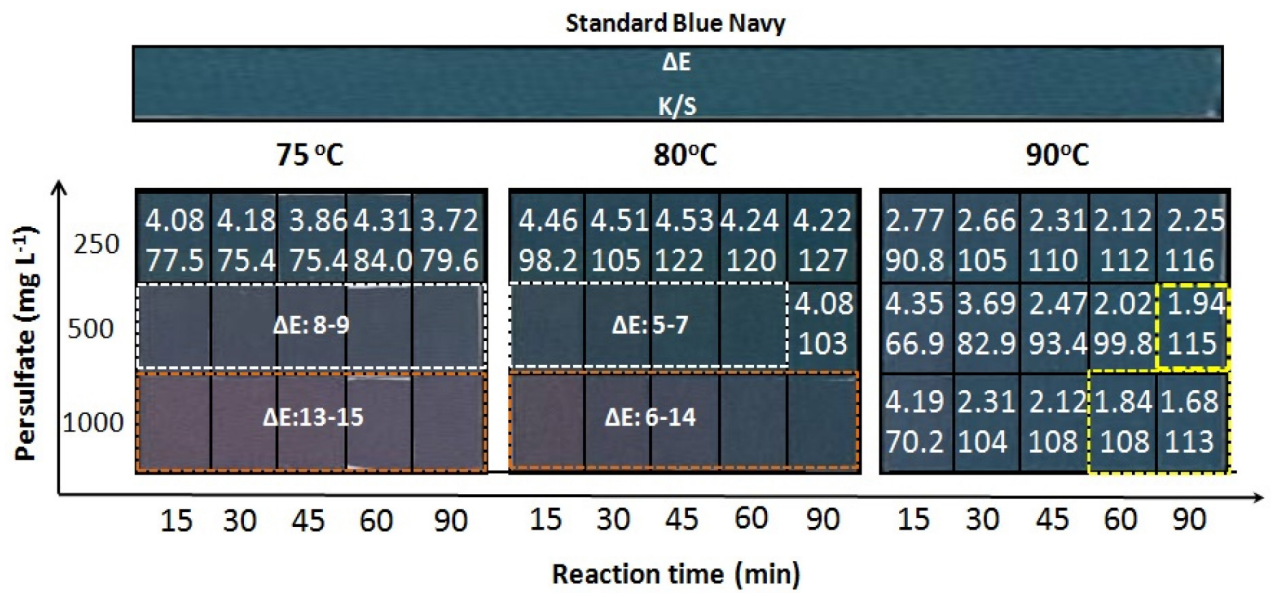

Figure 6. The color difference of fabrics dyed with dyebaths treated by thermally-activated persulfate.

was not significantly affected by the residual color. Also, higher concentrations of persulfate favored the removal of the color. Still, they made it difficult to reuse, probably due to residual persulfate that can promote partial degradation of the dyes during dyeing.

For $\Delta \mathrm{E}$ values below 5 , the color strength was always close to the optimum value (100\%), demonstrating an adequate dye uptake on the cotton fabrics. As this parameter is intimately related to various dyeing parameters, including the salt concentration, high values of the $\mathrm{K} / \mathrm{S}$ ratio indicate little influence of residual salts' presence from the previous dyeing process, suggesting that the addition of salts may be unnecessary for reuse.

\section{Conclusions}

Processes based on the use of thermally-activated persulfate effectively degrade reactive textile dyes, even in the presence of salts and auxiliary agents used in dyeing recipes of cotton fabrics. The persulfate decomposition leads to the generation of radical species, mainly radical sulfate, which degrades reactive dyes and quickly removes the color from the dyeing baths when applying the process at temperatures close to that of the rinsing process $\left(80^{\circ} \mathrm{C}\right)$. Treated baths were reused in new dyeing processes, observing good dyeing quality, mainly in treatments involving low persulfate concentrations $\left(250 \mathrm{mg} \mathrm{L}^{-1}\right)$. These results suggest a good potential of the process as a treatment routine directed to water reuse.

\section{Supplementary Information}

Supplementary information (dyeing procedure, kinetic adjustment of the discoloration process, and EPR spectrum of $\bullet$ DMPO- $\mathrm{SO}_{4}^{-}$) is available free of charge at http://jbcs. sbq.org.br as PDF file.

\section{Acknowledgments}

The authors thank the financial support granted by the 
Brazilian funding agencies, CAPES and CNPq, and the Electron Paramagnetic Resonance Laboratory (LabEPR/ UFPR).

\section{Author Contributions}

Amanda O. Basilio was responsible for writing original draft, investigation, writing-review and editing; Lucas Dohler, Matheus Servin for investigation; Carlos A. K. Gouvea, Ronny R. Ribeiro, Patricio Peralta-Zamora for conceptualization, writing-review and editing.

\section{References}

1. Lellis, B.; Fávaro-Polonio, C. Z.; Pamphile, J. A.; Polonio, J. C.; Biotechnol. Res. Innovation 2019, 3, 275.

2. Berradi, M.; Hsissou, R.; Khudhair, M.; Assouag, M.; Cherkaoui, O.; El Bachiri, A.; El Harfi, A.; Heliyon 2019, 5, e02711.

3. Rawat, D.; Sharma, R. S.; Karmakar, S.; Arora, L. S.; Mishra, V.; Ecotoxicol. Environ. Saf. 2018, 148, 528.

4. Bilińska, L.; Blus, K.; Foszpańczyk, M.; Gmurek, M.; Ledakowicz, S.; J. Environ. Manage. 2020, 265, 110502.

5. Al-Mamun, M. R.; Kader, S.; Islam, M. S.; Khan, M. Z. H.; J. Environ. Chem. Eng. 2019, 7, 103248.

6. Ertugay, N.; Acar, F. N.; Arabian J. Chem. 2017, 10, S1158.

7. Sandin, G.; Peters, G. M.; J. Cleaner Prod. 2018, 184, 353.

8. Hussain, T.; Wahab, A.; J. Cleaner Prod. 2018, 198, 806.

9. Holkar, C. R.; Jadhav, A. J.; Pinjari, D. V.; Mahamuni, N. M.; Pandit, A. B.; J. Environ. Manage. 2016, 182, 351.

10. Paździor, K.; Bilińska, L.; Ledakowicz, S.; Chem. Eng. J. 2019, 376, 120597.

11. Huang, Y.-R.; Kong, Y.; Li, H.-Z.; Wei, X.-M.; Environ. Technol. Innovation 2020, 18, 100780.

12. Yang, L.; Xue, J.; He, L.; Wu, L.; Ma, Y.; Chen, H.; Li, H.; Peng, P.; Zhang, Z.; Chem. Eng. J. 2019, 378, 122146.

13. Lu, J.; Zhou, Y.; Lei, J.; Ao, Z.; Zhou, Y.; Chemosphere 2020 , 251, 126402.

14. Liu, N.; Ding, F.; Weng, C. H.; Hwang, C. C.; Lin, Y. T.; J. Environ. Manage. 2018, 206, 565.

15. Ghauch, A.; Tuqan, A. M.; Kibbi, N.; Geryes, S.; Chem. Eng. J. 2012, 213, 259.

16. Merouani, S.; Hamdaoui, O.; Bouhelassa, M.; Desalin. Water Treat. 2017, 75, 202.

17. Ahmadi, S.; Igwegbe, C. A.; Rahdar, S.; Int. J. Ind. Chem. 2019 , 10, 249.

18. Samarghandi, M. R.; Tari, K.; Shabanloob, A.; Salarib, M.; Nasabc, H. Z.; Sep. Purif. Technol. 2020, 247, 116931.

19. Güneş, Y.; Bayraktar, İ.; Olmaz-Hanci, T.; Kaykığlu, G.; Desalin. Water Treat. 2018, 107, 296.
20. Liang, C.; Huang, C. F.; Mohanty, N.; Kurakalva, R. M.; Chemosphere 2008, 73, 1540.

21. Stoll, S.; Schweiger, A.; J. Magn. Reson. 2006, 178, 42.

22. MatLab, R2016a (9.0.0.341360); MathWorks Inc, Natick, MA, USA, 2016.

23. Origin (Pro) 9.0, version 2013; OriginLab Corporation, Northampton, MA, USA, 2013.

24. Chiarello, L. M.; Mittersteiner, M.; de Jesus, P. C.; Andreaus, J.; Barcellos, I. O.; J. Cleaner Prod. 2020, 267, 122033.

25. Allègre, C.; Moulin, P.; Maisseu, M.; Charbit, F.; J. Membr. Sci. 2006, 269, 15.

26. Milh, H.; Schoenaers, B.; Stesmans, A.; Cabooter, D.; Dewil, R.; Chem. Eng. J. 2020, 379, 122234.

27. Acero, J. L.; Benítez, F. J.; Real, F. J.; Rodríguez, E.; Sep. Purif. Technol. 2018, 201, 41.

28. Ike, I. A.; Linden, K. G.; Orbell, J. D.; Duke, M.; Chem. Eng. J. 2018, 338, 651.

29. Rao, M. P.; Wu, J. J.; Syed, A.; Ameen, F.; Anandan, S.; Mater. Res. Express 2018, 5, 015053.

30. Jager, D.; Kupka, D.; Vaclavikova, M.; Ivanicova, L.; Gallios, G.; Chemosphere 2018, 190, 405.

31. Bhaumik, M.; Maity, A.; Gupta, V. K.; J. Colloid Interface Sci. 2017, 506, 403.

32. Joseph, C. G.; Taufiq-Yap, Y. H.; Krishnan, V.; ASEAN J. Chem. Eng. 2017, 17, 37.

33. Bilal, M.; Rasheed, T.; Iqbal, H. M. N.; Hu, H.; Wang, W.; Zhang, X.; Environ. Manage. 2018, 61, 171.

34. Vasconcelos, V. M.; Ribeiro, F. L.; Migliorini, F. L.; Alves, S. A.; Steter, J. R.; Baldan, M. R.; Ferreira, N. G.; Lanza, M. R. V.; Electrochim. Acta 2015, 178, 484.

35. Zrinyi, N.; Pham, A. L. T.; Water Res. 2017, 120, 43.

36. Lourenço, N. D.; Menezes, J. C.; Pinheiro, H. M.; Diniz, D.; Environ. Technol. 2008, 29, 891.

37. Dilling, J.; Kaiser, K.; Water Res. 2002, 36, 5037.

38. Anipsitakis, G. P.; Dionysiou, D. D.; Environ. Sci. Technol. 2004, 38, 3705.

39. Liang, C.; Wang, Z. S.; Bruell, C. J.; Chemosphere 2007, 66, 106.

40. Bilski, P.; Reszka, K.; Bilska, M.; Chignell, C. F.; J. Am. Chem. Soc. 1996, 118, 1330.

41. Zalibera, M.; Rapta, P.; Staško, A.; Brindzová, L.; Brezová, V.; Free Radical Res. 2009, 43, 457.

42. Wei, Z.; Villamena, F. A.; Weavers, L. K.; Environ. Sci. Technol. 2017, 51, 3410 .

43. Taniguchi, H.; Madden, K. P.; J. Am. Chem. Soc. 1999, 121, 11875 .

44. DIN 6174: Farbmetrische Bestimmung Von Farbabständen bei Körperfarben nach der CIELAB- Formel, Beuth Verlag DINDeutsche Institut für Normung: Berlin und Köln, 1979.

Submitted: February 19, 2021

Published online: May 27, 2021 